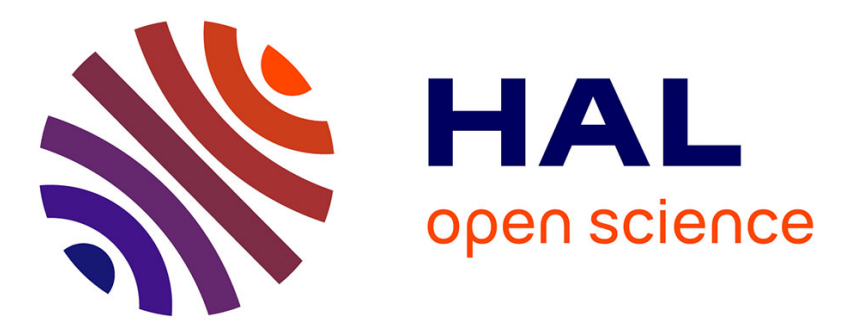

\title{
Facile synthesis of CuSe nanoparticles and high-quality single-crystal two-dimensional hexagonal nanoplatelets with tunable near-infrared optical absorption
}

\author{
Yimin Wu, Ilia Korolkov, Xvsheng Qiao, Xianghua Zhang, Jun Wan, \\ Xianping Fan
}

\section{To cite this version:}

Yimin Wu, Ilia Korolkov, Xvsheng Qiao, Xianghua Zhang, Jun Wan, et al.. Facile synthesis of CuSe nanoparticles and high-quality single-crystal two-dimensional hexagonal nanoplatelets with tunable near-infrared optical absorption. Journal of Solid State Chemistry, 2016, 238, pp.279-283. 10.1016/j.jssc.2016.03.048 . hal-01296811

\section{HAL Id: hal-01296811}

\section{https://hal-univ-rennes1.archives-ouvertes.fr/hal-01296811}

Submitted on 8 Jun 2016

HAL is a multi-disciplinary open access archive for the deposit and dissemination of scientific research documents, whether they are published or not. The documents may come from teaching and research institutions in France or abroad, or from public or private research centers.
L'archive ouverte pluridisciplinaire HAL, est destinée au dépôt et à la diffusion de documents scientifiques de niveau recherche, publiés ou non, émanant des établissements d'enseignement et de recherche français ou étrangers, des laboratoires publics ou privés. 
Facile synthesis of CuSe nanoparticles and high-quality single-crystal two-dimensional hexagonal nanoplatelets with tunable near-infrared optical absorption

Yimin $\mathrm{Wu}^{1}$, Ilia Korolkov ${ }^{2}$, Xvsheng Qiao ${ }^{1}$, Xianghua Zhang ${ }^{2}$, Jun Wan ${ }^{1}$, Xianping

$$
\operatorname{Fan}^{1 *}
$$

${ }^{1}$ State Key Laboratory of Silicon Materials, School of Materials Science and Engineering, Zhejiang University, Hangzhou 310027, P.R. China

${ }^{2}$ Laboratory of Glasses and Ceramics, Institute of Chemistry, CNRS-Université de Rennes I, campus de Beaulieu, 35042 Rennes cedex, France

Abstract

A rapid injection approach is used to synthesize the copper selenide nanoparticles and two-dimensional single crystal nanoplates. This technique excludes the use of toxic or expensive materials, increasing the availability of two-dimentional binary chalcogenide semicondutors. The structure of the nanocrystals has been studied and the possible formation mechanism of the nanoplates has been proposed. The optical absorption showed that the nanoplates demonstrated wide and tuneable absorption band in the visible and near infrared region. These nanoplates could be interesting for converting solar energy and for nanophotonic devices operating in the near infrared.

Keywords: copper selenide; nanoparticles and nanoplates; rapid injection approach; optical absorption 


\section{Introduction}

Recently, extensive attention has been paid to the preparation and characterization of metal-selenides mostly due to their unique electronic properties such as high concentration and mobility of electrons and temperature tunable band-gap [1-6]. These properties are of crucial importance for the design of nanoscale electronic components operating in near infrared [7, 8]. Among others, copper selenides (CS) is a particularly interesting class of materials due to its ability to form various stoichiometric and nonstoichiometric compounds. For instance, Riha et al. showed the possibility of tuning the electronic structure thanks to the controllable surface oxidation of $\mathrm{Cu}_{2} \mathrm{Se}$ (copper rich) nanoparticles, which allows a transition from $\mathrm{Cu}_{2} \mathrm{Se}$ monoclinic crystal cell to $\mathrm{Cu}_{1.8}$ Se cubic cell [9]. A detail description of the $\mathrm{Cu}_{2} \mathrm{Se}$ crystal structure can be found elsewhere $[10,11]$. At the same time, $\mathrm{CuSe}_{2}$ (copper poor) compounds were studied as a possible anion conductors due to the dominant chalcogen character at the Fermi level and consequent absence of electronic correlation inherent in copper rich compounds [12]. Between copper rich and copper poor compounds, a variety of stable and metastable phases such as $\mathrm{Cu}_{7} \mathrm{Se}_{4}, \mathrm{Cu}_{3} \mathrm{Se}_{2}$, CuSe exist in different crystallographic forms: orthorhombic, cubic, tetragonal, hexagonal etc [13]. It has been reported that copper selenides are p-type semiconductors whose thermal stability and band gap strongly depend on the stoichiometry and phase $[14,15]$. The tunability of the electronic properties upon the stoichiometry opens a vast filed of possible applications such as solar cells, optical filters, nanoswitches, thermoelectric and photoelectric energy convertors, 
superconductors [16-20].

Many attempts to prepare metal selenides nanomaterials in different stoichiometries and morphologies have been reported. The solution-phase synthetic method for CuSe was successfully utilized to obtain hexagonal nanoplates [21]. Synthesis route involving thermal decomposition of $\mathrm{Cu}\left(\mathrm{Se}=\mathrm{CNEt}_{2}\right)_{2}$ in refluxing 4-ethylpyridine solutions has also been described [22]. Platelet shaped nanostructures of CuSe have been also synthesized through solution phase reaction [23, 24]. The surfactant-thermal method for synthesis of metal chalcogenides attracted also an attention. The surfactant media could serve as a cheaper and multifunctional analogue of the ionic liquids, demonstrating suitability for the obtaining of metal-chalcogenide quantum dots, quantum wires, nanoplates and bulk crystals in a wide variety of stoichiometries altering synthesis time and surfactant solvent [25-28]. This method has demonstrated its efficiency also for synthesis of complex quaternary two-dimensional chalcogenides for photocatalytic and photovoltaic applications[29, 30]. However, the above mentioned and widely used methods are either toxic or complicated, time-consuming or energy inefficient. In this work, we report a new rapid-injection approach to prepare CuSe nanoplates with high quality single-crystal and two dimensional nanostructure. The mechanism of forming two-dimensional structure from nanoparticles will be proposed. To the best of our knowledge, this is the first report of this particular synthesis route for CuSe nanoplates which match the primitive hexagonal phase. This study opens a new way for energy-efficient, environment friendly and low cost controllable synthesis of binary chalcogenides. 


\section{Experimental}

The $\mathrm{Cu}_{\mathrm{x}}$ Se nanocrystals (NCs) were produced via a rapid injection approach [30] by reacting $\mathrm{CuCl}_{2} \cdot 2 \mathrm{H}_{2} \mathrm{O} 2 \mathrm{H}_{2} \mathrm{O}$ and $\mathrm{Al}\left(\mathrm{NO}_{3}\right)_{3} \cdot 9 \mathrm{H} 2 \mathrm{O}$ with an excess of selenium precursor in the presence of hexadecylamine (HDA). In a typical preparation, 1.5 mmol $\mathrm{CuCl}_{2} \cdot 2 \mathrm{H}_{2} \mathrm{O}\left(0.256 \mathrm{~g}, 99.99 \%\right.$, aladdin), $0.3 \mathrm{mmol} \mathrm{Al}\left(\mathrm{NO}_{3}\right)_{3} \cdot 9 \mathrm{H}_{2} \mathrm{O}(0.113 \mathrm{~g}$, 98\%, aladdin) , 15 mmol HDA (3.622g, 90\%, aladdin) and $30 \mathrm{~mL}$ octadecene (ODE, 90\%, Aldrich) were introduced inside a three-neck flask and heated to $200{ }^{\circ} \mathrm{C}$ under argon flow until all precursors were dissolved. Afterward, the obtained yellowish transparent solution was cooled to $180{ }^{\circ} \mathrm{C}$ and maintained under Ar flow for half an hour to remove oxygen, water and other volatile impurities. Then $12 \mathrm{~mL}$ ODE-Se (0.8 M) solution was rapidly injected through a syringe. The excess selenium leaded to the instantaneous formation of nuclei of metal selenides, guarantees the uniformity of grain size and hinders the growth behavior during the grain nucleation. And it could also insure a complete reaction. The mixture was maintained at $180{ }^{\circ} \mathrm{C}$ from 0 min up to $60 \mathrm{~min}$. Afterward, the solution was rapidly cooled down to room temperature in air. The generation of $\mathrm{Cu}_{\mathrm{x}} \mathrm{Se}$ nanocrystallines was evidenced by the color change of the mixture from an initial light orange to eventually deep green color of the solution. To remove the weakly bound HDA, $9 \mathrm{ml}$ of oleic acid (OA, 90\%, Aldrich) was added to the mixture during the cooling step at about $70^{\circ} \mathrm{C}$ [31]. And finally the nanocrystals were isolated and purified using chloroform and isopropanol to complete the standard solvent/nonsolvent precipitation/redispersion procedure and were dried under vacuum at $40^{\circ} \mathrm{C}$ for about $12 \mathrm{hr}$. 


\section{ACCEPTED MANUSCRIPT}

Transmission electron microscopy (TEM) images were obtained with a Philips CM200 field emission microscope. High resolution transmission electron microscopy (HRTEM) images with selected area electron diffraction (SAED) patterns and Energy Dispersive Spectrometer (EDS) data were obtained with a FEI Tecnai G2 F20 field emission microscope. A Hitachi S-4800 field emission scanning electron microscope was used to observe the morphology. X-ray diffraction (XRD) analysis was carried out on a PANalytical B.V Empyrean 200895 X-ray diffractometer. UV-VIS absorption spectra were taken with a SHIMADZU UV-3150 spectrophotometer.

\section{Results and discussion}

Fig.1 shows the XRD patterns of the copper selenides nanoparticles and nanoplates which were synthesized at $180^{\circ} \mathrm{C}$ for different time with the presence of $\mathrm{Al}\left(\mathrm{NO}_{3}\right)_{3} \cdot 9 \mathrm{H}_{2} \mathrm{O}$. Wide and relatively weak diffraction peaks can be clearly observed for nanocrystals obtained after less than 10 min synthesis. Moreover their patterns do not accurately correspond to CuSe JCPDS card. This is due to the presence of the big amount of relatively small nanocrystals with slight deviation from the stoichiometry. Extending of the reaction time up to 60 min leads to the enhancement of (006) diffraction peak attributed to hexagonal CuSe. The increase of diffraction intensity in several orders of magnitude and the narrowing of the diffraction peaks indicated a rapid growth of CuSe nanocrystals from smaller aggregates. It is worth mentioning that no XRD peaks of the Se crystals or the other secondary phase were detected.

Fig.2 shows the TEM images of the copper selenides nanoparticles and 


\section{ACCEPTED MANUSCRIPT}

nanoplates which were synthesized at $180^{\circ} \mathrm{C}$ for different time with the presence of $\mathrm{Al}\left(\mathrm{NO}_{3}\right)_{3} \cdot 9 \mathrm{H}_{2} \mathrm{O}$. The average size of the spherical nanocrystals increased from $10 \mathrm{~nm}$ to about $30 \mathrm{~nm}$ after 10 min synthesis. These spherical nanocrystals were eventually transformed to regular-shape triangular and hexagonal nanoplates after $60 \mathrm{~min}$ synthesis. Inserts in fig. 2 a and b show the measured size distribution confirming that 10 min synthesis was enough to obtain quasi-spherical CuSe nanocrystals with narrow size distribution. HRTEM images (Fig.2 d, e) show that the typical lattice spacing of the CuSe nanoparticles and nanoplates is $3.56 \AA$, which is in good agreement with the standard value for (220) plane of CuSe hexagonal phase. The SAED pattern (insert of fig.2c) demonstrates ordered diffraction spots which could be attributed to the primitive hexagonal structure of copper selenide with the zone axis along the (006) plane direction. This indicates that the nanoplates were well crystallized and have a single-crystal nature. Fig.2f shows the SEM image of the copper selenides nanoplates which were synthesized at $180^{\circ} \mathrm{C}$ for $60 \mathrm{~min}$. The regular hexagonal and triangle plates with about $50 \mathrm{~nm}$ thickness could be observed.

Fig.3 shows energy dispersive spectroscopy (EDS) of the copper selenides nanoparticles and nanoplates which were synthesized at $180^{\circ} \mathrm{C}$ for different time with the presence of $\mathrm{Al}\left(\mathrm{NO}_{3}\right)_{3} \cdot 9 \mathrm{H}_{2} \mathrm{O}$, which indicated the absence of $\mathrm{Al}$ inside the nanoparticles. The presence of $\mathrm{Al}^{3+}$ tends to attracted not only $\mathrm{Cl}^{-}$but also negatively charged selenium ions that lead to the slower growth of CuSe nanoplates. From EDS results, it can be estimated that the $\mathrm{Cu} / \mathrm{Se}$ ratio of the nanoparticles which were synthesized at $180^{\circ} \mathrm{C}$ for 0 min was $50 / 50$. The nanoparticles which were synthesized 
at $180^{\circ} \mathrm{C}$ for 10 min show slight deviation from the stoichiometry (47/53). A significant Se excess with a ratio of 37/63 could be observed for the copper selenides nanoplates which were synthesized at $180^{\circ} \mathrm{C}$ for $60 \mathrm{~min}$. However, XRD result (Fig.1) shows that only CuSe hexagonal phase was formed in the nanoplates which were synthesized at $180^{\circ} \mathrm{C}$ for 60 min, which indicated that nanoplates followed CuSe hexagonal phase even in case of Se-excess.

Copper selenide is a well-known p-type semiconductor possessing a direct band gap with $\mathrm{E}_{\mathrm{g}}$ depending on the stoichiometry and varying from $1.0 \mathrm{eV}$ to $2.0 \mathrm{eV}$. [13] According to Chen et al. [8], the $\mathrm{Cu}$ vacancies $\left(\mathrm{V}_{\mathrm{Cu}}\right)$ created a shallow acceptor level close to the valence band. This self-doping effect was responsible for p-type conductivity of CuSe. For the elucidation of the electronic properties, UV-VIS-NIR absorption spectra were recorded. Since copper selenide is a direct band semiconductor the optical absorption data could be calculated from diffuse reflectance data using Kubelka-Munk equations: $F(R)=\alpha / \Lambda=(1-R)^{2} /(2 R)$, where $R$ is the reflectance, $\alpha$ and $\Lambda$ are the absorption and scattering coefficients, respectively [32]. Fig.4 shows the plots of $[\mathrm{F}(\mathrm{R}) \mathrm{h} v]^{2}$ versus energy $(\mathrm{h} v)$ for the copper selenides nanoparticles and nanoplates which were synthesized at $180^{\circ} \mathrm{C}$ for different time. It was estimated $\mathrm{E}_{\mathrm{g}}$ is $1.29 \mathrm{eV}$ for $0 \mathrm{~min} .1 .18 \mathrm{eV}$ for $10 \mathrm{~min}$ and $1.52 \mathrm{eV}$ for $60 \mathrm{~min}$. The red shift for nanocrystals obtained after 10 min reaction can be explained from the point of view of quantum confinement, since the size of 0 min synthesized nanocrystals was about $10 \mathrm{~nm}$, the same order of magnitude as the De Broglie wavelength of a free electron. Therefore the quantum confinement effect can be 


\section{ACCEPTED MANUSCRIPT}

significant to increase the band gap width of nanocrystals, compared to a bulk material. Increase of nanocrystal size reduces the influence of quantum confinement on the electronic structure. However this does not explain the strong blue shift for the 60 min synthesized nanocrystals. In fact, in the above mentioned EDS pattern (Fig.3), one can see that 60 min synthesized nanocrystals possess an excess of Se, which can lead to the formation of $\mathrm{Se}_{\mathrm{Cu}}$ type of defects. The increase of the electronegative element (Se) in a CuSe crystal cell in its turn causes significant widening of the band gap. This result provides a possibility of controlling the $\mathrm{E}_{\mathrm{g}}$ simply by controlling the synthesized time.

In order to determine the role of $\mathrm{Al}^{3+}$ in CuSe nanocrystals growth, the copper selenides nanoparticles and nanoplates were synthesized in the absence of $\mathrm{Al}\left(\mathrm{NO}_{3}\right)_{3} \cdot 9 \mathrm{H}_{2} \mathrm{O}$. Fig. 5 shows the XRD patterns of the copper selenides nanoparticles and nanoplates synthesized at $180^{\circ} \mathrm{C}$ for different time without the presence of $\mathrm{Al}\left(\mathrm{NO}_{3}\right)_{3} \cdot 9 \mathrm{H}_{2} \mathrm{O}$. The 0 min synthesized sample corresponds to an unknown phase and consists of a big amount of small crystals. However, obvious (006) diffraction peak corresponding to CuSe hexagonal phase can be observed in the 10 min synthesized sample, which indicated a rapid growth of hexagonal CuSe crystals in the absence of $\mathrm{Al}\left(\mathrm{NO}_{3}\right)_{3} \cdot 9 \mathrm{H}_{2} \mathrm{O}$. Fig.6 shows the TEM images of the copper selenides nanoparticles and nanoplates synthesized at $180^{\circ} \mathrm{C}$ for different time without the presence of $\mathrm{Al}\left(\mathrm{NO}_{3}\right)_{3} \cdot 9 \mathrm{H}_{2} \mathrm{O}$. The 0 min synthesized sample shows the regular spherical nanoparticles with narrow size distribution. These spherical nanoparticles were rapidly transformed to regular-shape triangular and hexagonal CuSe nanoplates only 
after 10 min synthesis, which indicated that the absence of $\mathrm{Al}^{3+}$ leads to faster growth of CuSe nanoplates.

It was demonstrated that spherical nanoparticles were formed initially and then these particles are progressively aggregated together to form triangular and hexagonal nanoplates. The likely mechanism of nanoplates assembly is proposed in fig.6. Oriented attachment involves spontaneous self-organization including rotation and migration of adjacent particles, thus they share a common crystallographic orientation, followed by joining of these particles at a planar interface [33, 34]. Aggregation of nanocrystals in nanoplates is energetically beneficial since it reduces the overall length of nanocrystal-ligand interface and therefore leads to the reduction of Gibbs energy by removing surface-associated states. As it can be seen from HRTEM image of the intermediate product (Fig.2d), the nanocrystals evidently demonstrate mutual orientation and aggregation according to the oriented attachment mechanism leading to the formation of two-dimensional single crystal nanoplates.

\section{Conclusions}

The copper selenide nanoparticles and high-quality single-crystal two-dimensional hexagonal nanoplatelets have been synthesized by a rapid injection approach. The possible growth mechanism of the nanoplates is based on the "oriented attachment" nanoparticles. During the synthesis process, $\mathrm{Al}^{3+}$ ions in the solution have a significant impact on the growth rate of the nanoplates. It is demonstrated that CuSe band gap can be widely tuned simply by modifying the synthesized time. This gives 


\section{ACCEPTED MANUSCRIPT}

the possibility to adjust this important parameter of this interesting semiconductor according to the targeted applications.

Acknowledgements

The authors gratefully acknowledge support for this research from the Program for Innovative Research Team in University of Ministry of Education of China (IRT13R54) and the Fundamental Research Funds for the Central Universities (2015FZA4008).

\section{References}

[1] M. Esmaeili-Zare, M. Salavati-Niasari, A. Sobhani, Simple sonochemical synthesis and characterization of HgSe nanoparticles, Ultrason. Sonochem., 19 (2012) 1079-1086.

[2] M. Afzaal, P. O'Brien, Recent developments in II-VI and III-VI semiconductors and their applications in solar cells, J. Mater. Chem., 16 (2006) 1597-1602.

[3] A. Zakutayev, D. McIntyre, G. Schneider, R. Kykyneshi, D. Keszler, C.-H. Park, J. Tate, Tunable properties of wide-band gap p-type $\mathrm{BaCu}\left(\mathrm{Ch}_{1-\mathrm{x}} \mathrm{Ch}_{\mathrm{x}}{ }^{\prime}\right) \mathrm{F}(\mathrm{Ch}=\mathrm{S}, \mathrm{Se}, \mathrm{Te})$ thin-film solid solutions, Thin Solid Films, 518 (2010) 5494-5500.

[4] M. Salavati-Niasari, M. Esmaeili-Zare, A. Sobhani, Synthesis and characterisation of cadmium selenide nanostructures by simple sonochemical method, Micro \& Nano Letters, 7 (2012) 831-834.

[5] C.-N. Zhu, P. Jiang, Z.-L. Zhang, D.-L. Zhu, Z.-Q. Tian, D.-W. Pang, Ag2Se quantum dots with tunable emission in the second near-infrared window, ACS Appl. 
Mat. Interfaces, 5 (2013) 1186-1189.

[6] M.-A. Langevin, D. Lachance-Quirion, A.M. Ritcey, C.N. Allen, Size-Dependent Extinction Coefficients and Transition Energies of Near-Infrared $\beta$-Ag ${ }_{2}$ Se Colloidal Quantum Dots, J. Phys. Chem. C, 117 (2013) 5424-5428.

[7] J. Ren, D. Eason, L. Churchill, Z. Yu, C. Boney, J. Cook, J. Schetzina, N. El-Masry, Integrated heterostructure devices composed of II-VI materials with Hg-based contact layers, J. Cryst. Growth, 138 (1994) 455-463.

[8] O. Chen, X. Chen, Y. Yang, J. Lynch, H. Wu, J. Zhuang, Y.C. Cao, Synthesis of metal-selenide nanocrystals using selenium dioxide as the selenium precursor, Angew. Chem. Int. Ed., 47 (2008) 8638-8641.

[9] S.C. Riha, D.C. Johnson, A.L. Prieto, $\mathrm{Cu}_{2} \mathrm{Se}$ nanoparticles with tunable electronic properties due to a controlled solid-state phase transition driven by copper oxidation and cationic conduction, J. Am. Chem. Soc., 133 (2010) 1383-1390.

[10] S. Kashida, J. Akai, X-ray diffraction and electron microscopy studies of the room-temperature structure of $\mathrm{Cu}_{2} \mathrm{Se}$, J Phys C Solid State Phys, 21 (1988) 5329.

[11] K. Yamamoto, S. Kashida, X-ray study of the average structures of $\mathrm{Cu}_{2} \mathrm{Se}$ and $\mathrm{Cu}_{1.8} \mathrm{~S}$ in the room temperature and the high temperature phases, J. Solid State Chem., 93 (1991) 202-211.

[12] H. Ueda, M. Nohara, K. Kitazawa, H. Takagi, A. Fujimori, T. Mizokawa, T. Yagi, Copper pyrites $\mathrm{CuS}_{2}$ and $\mathrm{CuSe}_{2}$ as anion conductors, Phys. Rev. B: Condens. Matter, 65 (2002) 155104.

[13] R.D. Heyding, R.M. Murray, The crystal structures of $\mathrm{Cu}_{1.8} \mathrm{Se}, \mathrm{Cu}_{3} \mathrm{Se}_{2}, \alpha$-and 
rCuSe, $\mathrm{CuSe}_{2}$, and CuSe 2 II, Can. J. Chem., 54 (1976) 841-848.

[14] Z. Han, Y. Li, H. Zhao, S. Yu, X. Yin, Y. Qian, A simple solvothermal route to copper chalcogenides, Mater. Lett., 44 (2000) 366-369.

[15] A. Schäfer, M. Kollwitz, R. Ahlrichs, Electronic excitation energies in copper selenide clusters, J. Chem. Phys., 104 (1996) 7113-7121.

[16] P. Nair, M. Nair, V. Garcı, O. Arenas, Y. Pena, A. Castillo, I. Ayala, O. Gomezdaza, A. Sanchez, J. Campos, Semiconductor thin films by chemical bath deposition for solar energy related applications, Sol. Energy Mater. Sol. Cells, 52 (1998) 313-344.

[17] M. Korzhuev, Dufour effect in superionic copper selenide, Phys Solid State, 40 (1998) 217-219.

[18] P. Hankare, V. Bhuse, K. Garadkar, S. Delekar, I. Mulla, Low temperature route to grow polycrystalline cadmium selenide and mercury selenide thin films, Mater. Chem. Phys., 82 (2003) 711-717.

[19] H. Pathan, C. Lokhande, Deposition of metal chalcogenide thin films by successive ionic layer adsorption and reaction (SILAR) method, Bull. Mater. Sci., 27 (2004) 85-111.

[20] D. Lippkow, H.-H. Strehblow, Structural investigations of thin films of copperselenide electrodeposited at elevated temperatures, Electrochim. Acta, 43 (1998) 2131-2140.

[21] T. Vinod, X. Jin, J. Kim, Hexagonal nanoplatelets of CuSe synthesized through facile solution phase reaction, Mater. Res. Bull., 46 (2011) 340-344. 
[22] M.A. Malik, P. O'Brien, N. Revaprasadu, A novel route for the preparation of CuSe and CuInSe 2 nanoparticles, Adv. Mater., 11 (1999) 1441-1444.

[23] X. Zheng, Q. Hu, Facile synthesis and phase control of copper chalcogenides with different morphologies, Appl Phys A Mater Sci Process, 94 (2009) 805-812.

[24] Z. Deng, M. Mansuripur, A.J. Muscat, Synthesis of two-dimensional single-crystal berzelianite nanosheets and nanoplates with near-infrared optical absorption, J. Mater. Chem., 19 (2009) 6201-6206.

[25] W.W. Xiong, J.W. Miao, K.Q. Ye, Y. Wang, B. Liu, Q.C. Zhang, Threading Chalcogenide Layers with Polymer Chains, Angew. Chem. Int. Ed., 54 (2015) 546-550.

[26] W.W. Xiong, Q. Zhang, Surfactants as Promising Media for the Preparation of Crystalline Inorganic Materials, Angew. Chem. Int. Ed., 54 (2015) 11616-11623.

[27] W.W. Xiong, G. Zhang, Q. Zhang, New strategies to prepare crystalline chalcogenides, Inorg. Chem. Front., 1 (2014) 292-301.

[28] W.W. Xiong, E.U. Athresh, Y.T. Ng, J. Ding, T. Wu, Q. Zhang, Growing crystalline chalcogenidoarsenates in surfactants: From zero-dimensional cluster to three-dimensional framework, J. Am. Chem. Soc., 135 (2013) 1256-1259.

[29] W.W. Xiong, P.Z. Li, T.H. Zhou, A.I.Y. Tok, R. Xu, Y. Zhao, Q. Zhang, Kinetically controlling phase transformations of crystalline mercury selenidostannates through surfactant media, Inorg. Chem., 52 (2013) 4148-4150.

[30] W.W. Xiong, J. Miao, P.Z. Li, Y. Zhao, B. Liu, Q. Zhang, [enH][Cu $\left.\mathrm{AgSnS}_{4}\right]$ : a quaternary layered sulfide based on $\mathrm{Cu}-\mathrm{Ag}-\mathrm{Sn}-\mathrm{S}$ composition, CrystEngComm, 16 
(2014) 5989-5992.

[31] W. Li, R. Zamani, M. Ibanez, D. Cadavid, A. Shavel, J.R. Morante, J. Arbiol, A. Cabot, Metal ions to control the morphology of semiconductor nanoparticles: copper selenide nanocubes, J. Am. Chem. Soc., 135 (2013) 4664-4667.

[32] Z. Deng, D. Chen, B. Peng, F. Tang, From bulk metal Bi to two-dimensional well-crystallized $\mathrm{BiOX}(\mathrm{X}=\mathrm{Cl}, \mathrm{Br})$ micro-and nanostructures: synthesis and characterization, Cryst. Growth Des., 8 (2008) 2995-3003.

[33] K.-S. Cho, D.V. Talapin, W. Gaschler, C.B. Murray, Designing PbSe nanowires and nanorings through oriented attachment of nanoparticles, J. Am. Chem. Soc., 127 (2005) 7140-7147.

[34] C. Schliehe, B.H. Juarez, M. Pelletier, S. Jander, D. Greshnykh, M. Nagel, A. Meyer, S. Foerster, A. Kornowski, C. Klinke, Ultrathin PbS sheets by two-dimensional oriented attachment, Science, 329 (2010) 550-553. 


\section{Caption of figures}

Fig.1 XRD patterns of the copper selenides nanoparticles and nanoplates synthesized at $180^{\circ} \mathrm{C}$ for different time with the presence of $\mathrm{Al}\left(\mathrm{NO}_{3}\right)_{3} \cdot 9 \mathrm{H}_{2} \mathrm{O}$.

Fig.2 TEM images of the copper selenides nanoparticles and nanoplates synthesized at $180^{\circ} \mathrm{C}$ for (a) 0 min, (b) $10 \mathrm{~min}$, (c) 60 min. (d) HRTEM images of (a), (e) HRTEM images of (c), and (f) SEM images of copper selenide hexagonal nanoplates synthesized at $180^{\circ} \mathrm{C}$ for $60 \mathrm{~min}$.

Fig.3 Energy dispersive spectroscopy (EDS) of the copper selenides nanoparticles and nanoplates synthesized at $180^{\circ} \mathrm{C}$ for different time with the presence of $\mathrm{Al}\left(\mathrm{NO}_{3}\right)_{3} \cdot 9 \mathrm{H}_{2} \mathrm{O}$.

Fig.4 Absorption spectra of the copper selenides nanoparticles and nanoplates synthesized at $180^{\circ} \mathrm{C}$ for different time.

Fig.5 XRD patterns of the copper selenides nanoparticles and nanoplates synthesized at $180^{\circ} \mathrm{C}$ for different time without the presence of $\mathrm{Al}\left(\mathrm{NO}_{3}\right)_{3} \cdot 9 \mathrm{H}_{2} \mathrm{O}$.

Fig.6 TEM images of the copper selenides nanoparticles and nanoplates synthesized at $180^{\circ} \mathrm{C}$ for (a) $0 \mathrm{~min}$, (b) $10 \mathrm{~min}$, and (c) $60 \mathrm{~min}$ without the presence of $\mathrm{Al}\left(\mathrm{NO}_{3}\right)_{3} \cdot 9 \mathrm{H}_{2} \mathrm{O}$.

Fig.7 Growth mechanism of the copper selenide nanoplates via the "oriented attachment". 


\section{ACCEPTED MANUSCRIPT}

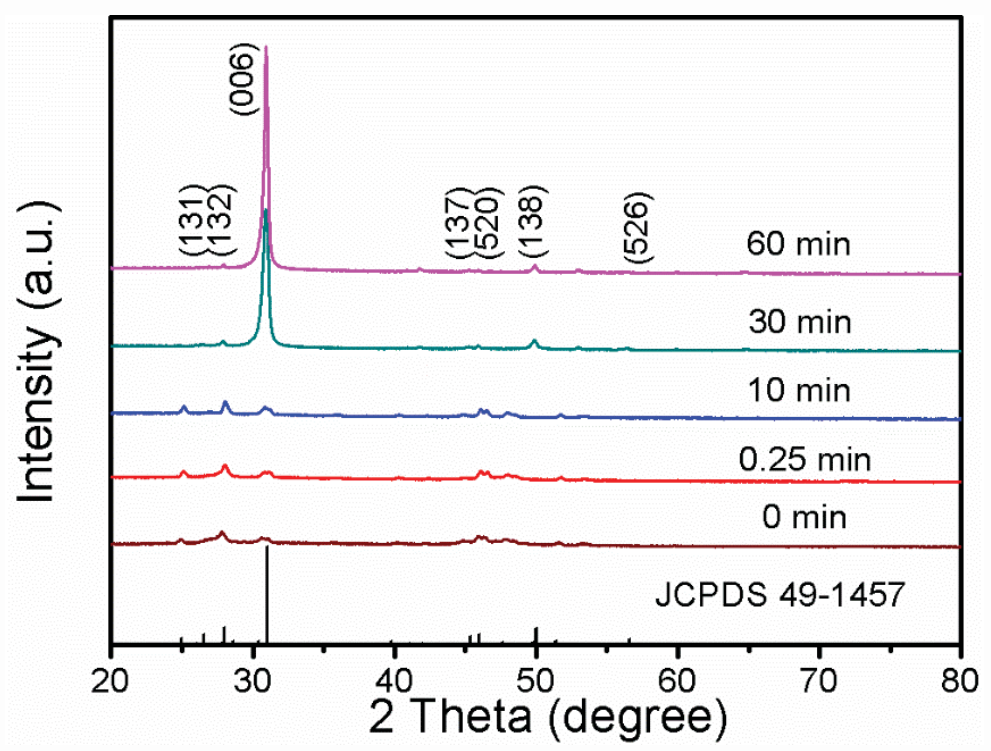

Fig.1

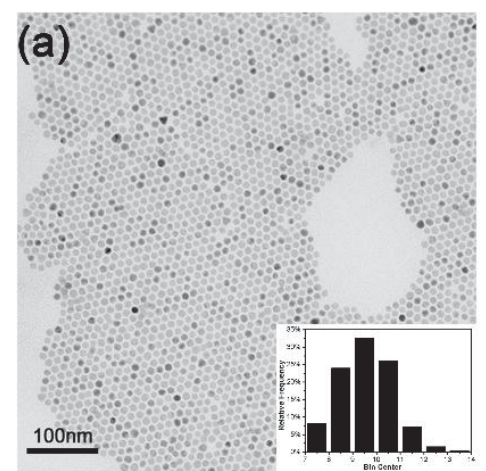

(d)

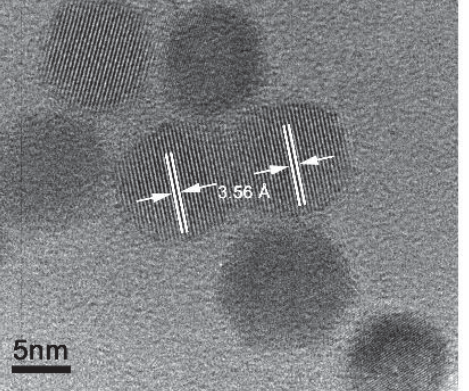

(b)

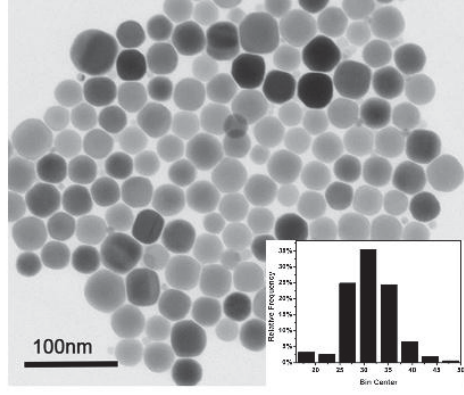

(e)

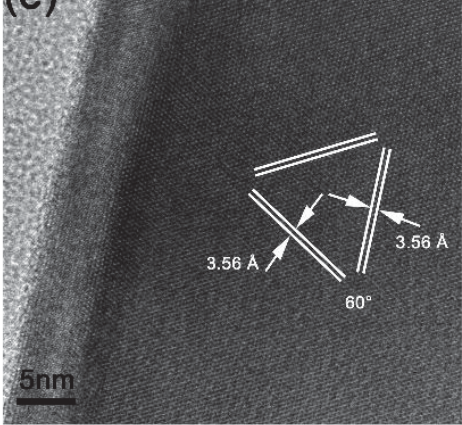

Fig.2 (c)
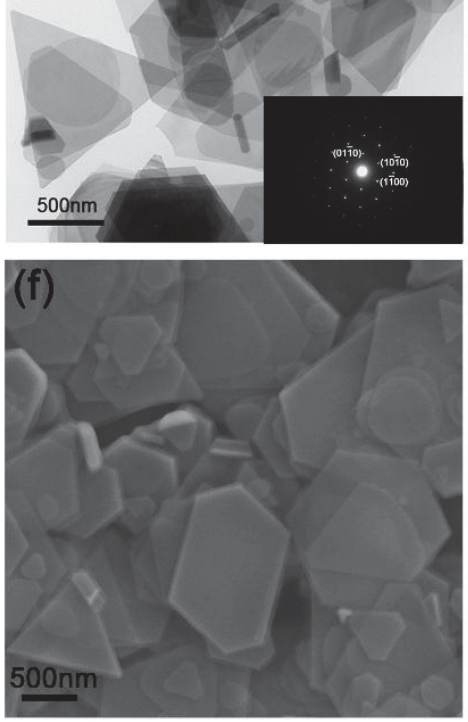


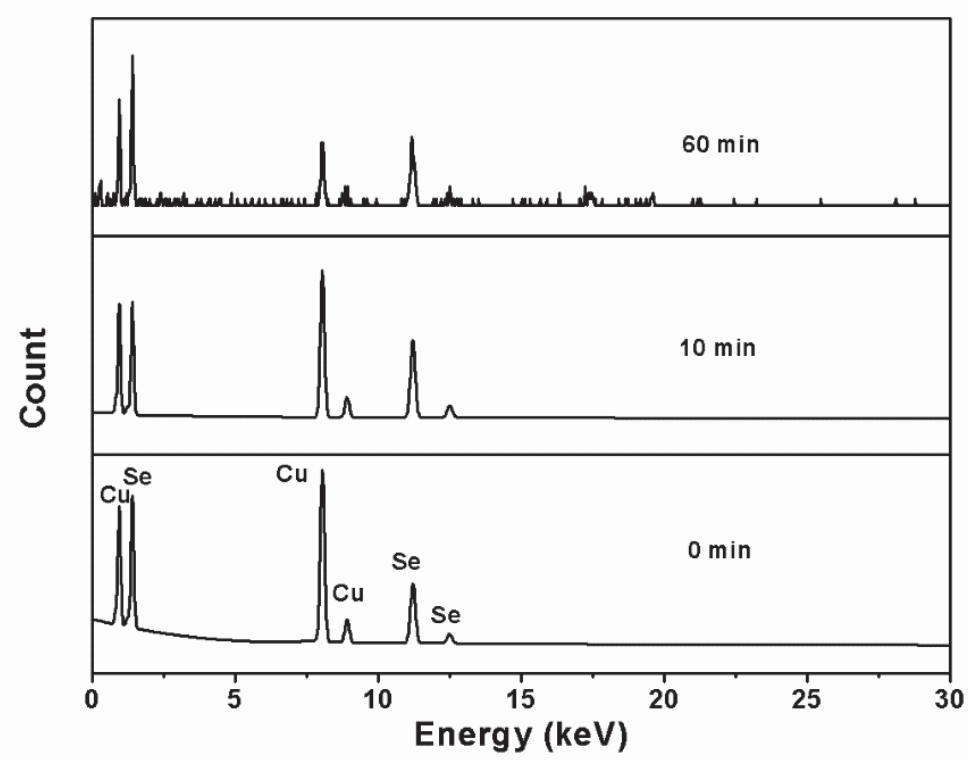

Fig.3

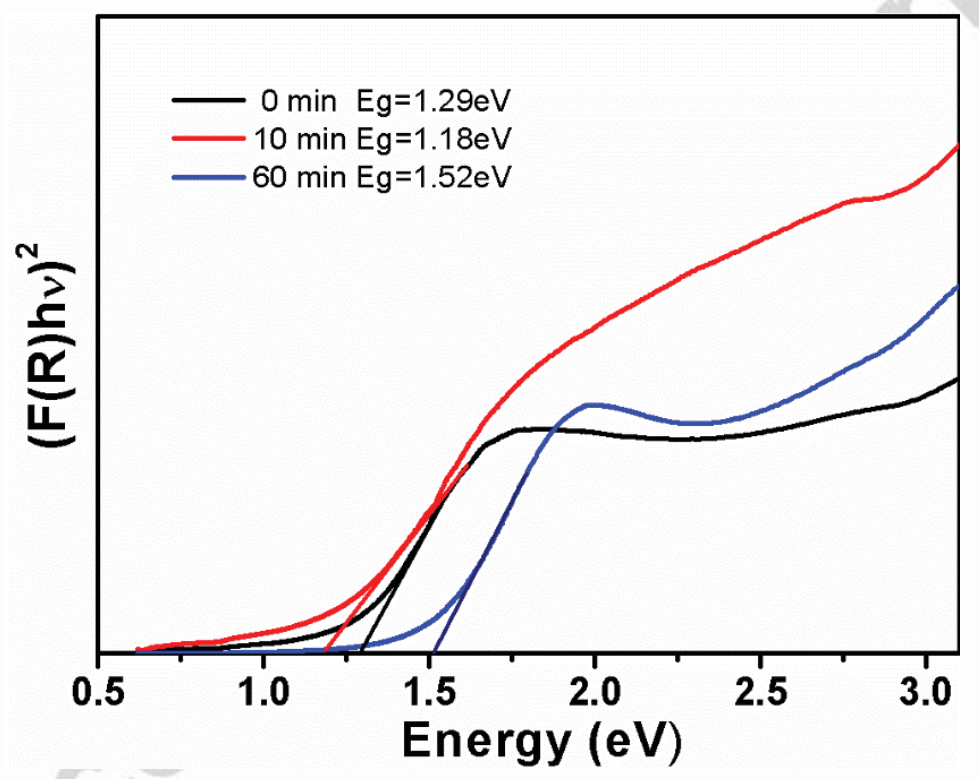

Fig.4 


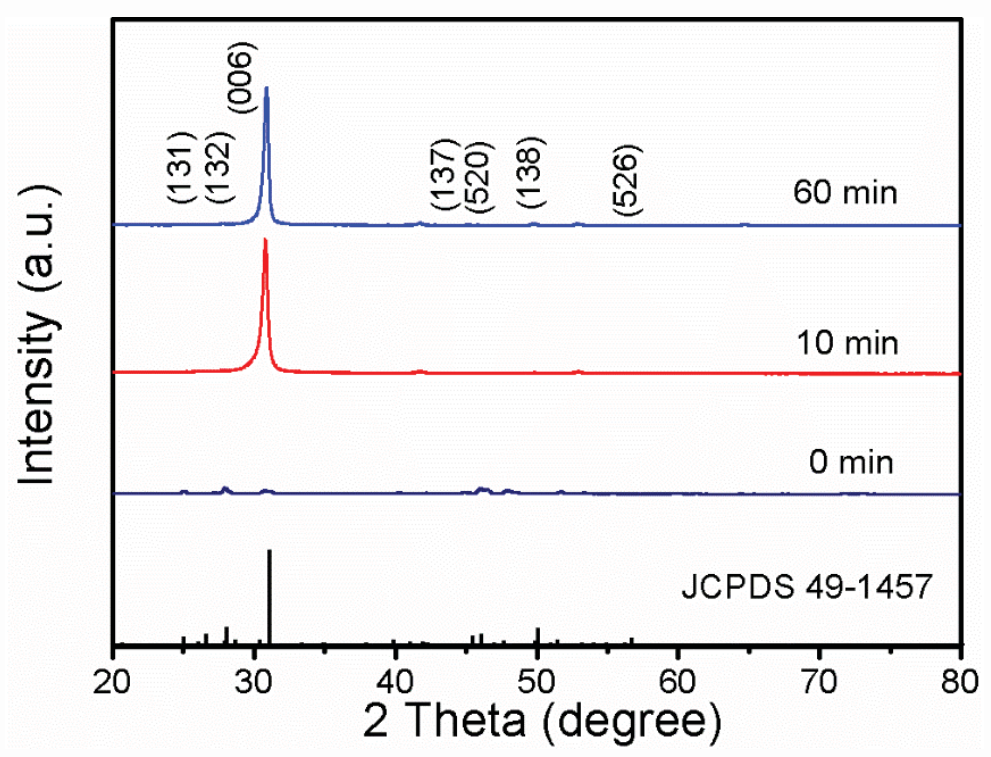

Fig.5
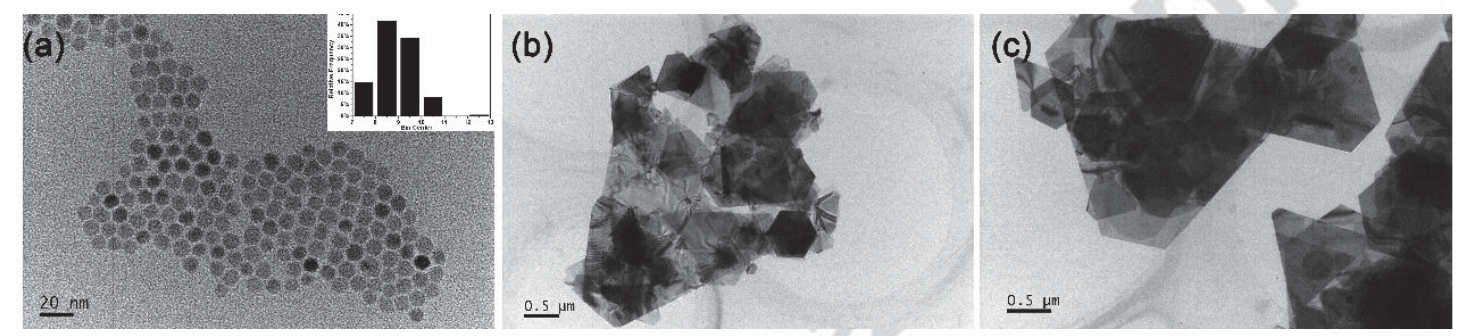

Fig.6

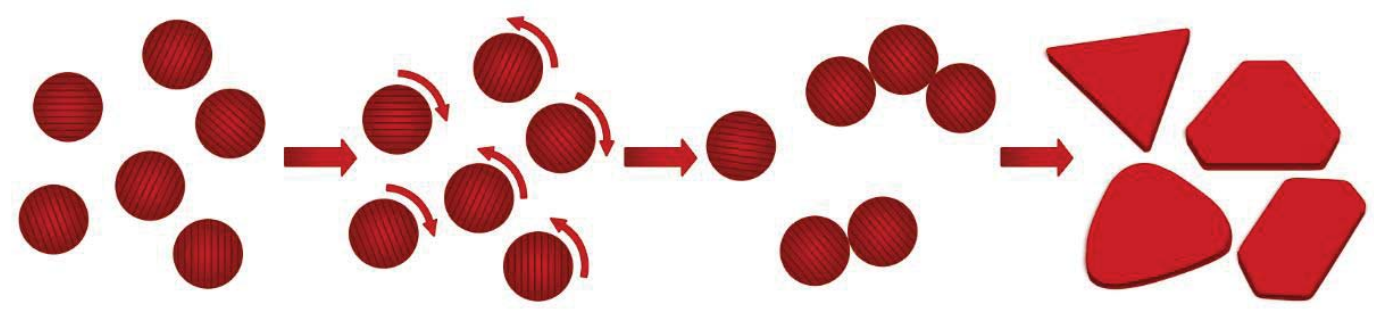

Fig.7

Graphical Abstract 


\section{ACCEPTED MANUSCRIPT}

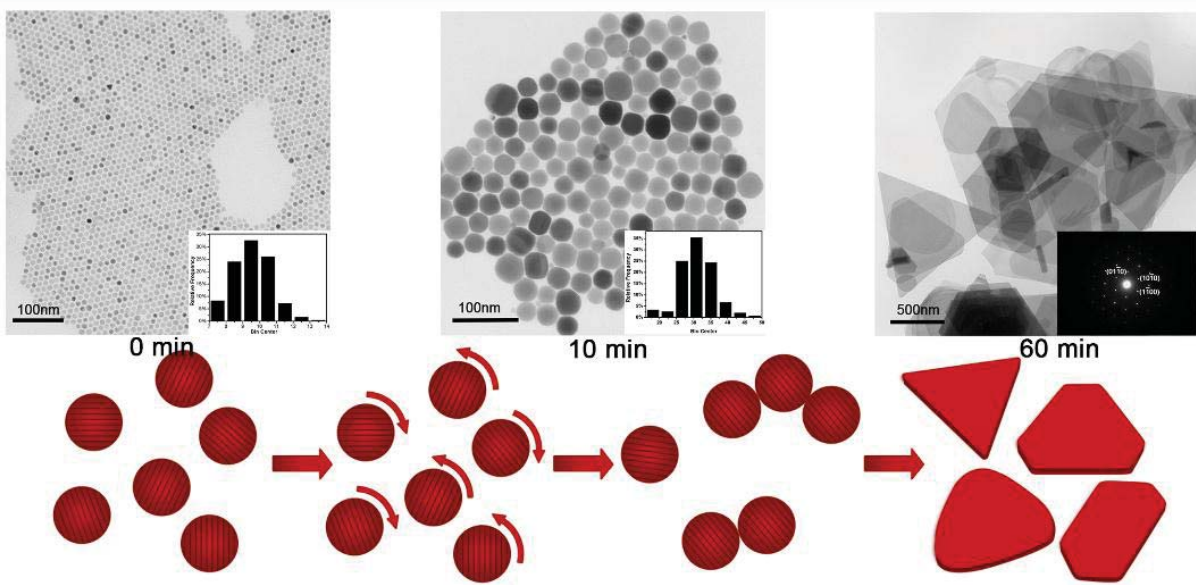

TEM images of the copper selenides nanoparticles and nanoplates synthesized at $180^{\circ} \mathrm{C}$ for $0 \mathrm{~min}, 10 \mathrm{~min}, 60 \mathrm{~min}$. And the growth mechanism of the copper selenide nanoplates via the "oriented attachment".

\section{Highlights:}

- CuSe nanoparticles and nanoplates are synthesized by a rapid injection approach.

- CuSe band gap can be widely tuned simply by modifying the synthesized time.

- $\mathrm{Al}^{3+}$ ions have a significant impact on the growth rate of the nanoplates.

- Growth mechanism of the CuSe nanoplates is based on the "oriented attachment". 